UNIVERSIDADE ESTADUAL DE FEIRA DE SANTANA

Autorizada pelo Decreto Federal $n^{0} 77.496$ de 27/04/76

Recredenciamento pelo Decreto $n^{\circ} 17.228$ de 25/11/2016

PPPG

PRÓ-REITORIA DE PESQUISA E PÓS-GRADUAÇÃO

COORDENAÇÃO DE INICIAÇÃO CIENTÍFICA

XXIII SEMINÁRIO DE INICIACC̃̃O CIENTÍFICA DA UEFS

SEMANA NACIONAL DE CIENTÍFICA E TECNOLÓGICA - 2019

\title{
"ENSINO ATUALIZADO DA MATEMÁTICA" PARA O SÉTIMO ANO DO PRIMEIRO GRAU E SEU GUIA DO PROFESSOR: CONTEÚDOS, RECOMENDAÇÕES E ORIENTAÇÕES DE UMA GEOMETRIA A ENSINAR E PARA ENSINAR
}

\author{
$\underline{\text { Deisiane Simões Santana }}^{1}$; Rosemeire de Fatima Batistela ${ }^{2}$; Eliene Barbosa Lima ${ }^{3}$ \\ 1. Bolsista PIBIC/FAPESB, Graduanda em Licenciatura em Matemática, Universidade Estadual de Feira de Santana, \\ e-mail: deisy.simoe@gmail.com \\ 2. Orientadora, Departamento Ciências Exatas (DEXA), Universidade Estadual de Feira de Santana, e-mail: \\ rosebatistela@gmail.com \\ 3. Participante do projeto, Ciências Exatas (DEXA), Universidade Estadual de Feira de Santana, e-mail: \\ elienebarbosalima@gmail.com
}

PALAVRAS-CHAVE: Livro Didático. Ensino de Geometria. Teorias Modernas da Matemática.

\section{INTRODUÇÃO}

Essa análise foi desenvolvida no âmbito do Projeto de Pesquisa, dito Guarda-Chuva, intitulado "As teorias modernas da matemática nos livros didáticos das instituições educacionais superiores e secundárias brasileiras e baianas", regularizado na Universidade Estadual de Feira de Santana sob a Resolução CONSEPE 130/2013.

Dessa forma, este trabalho de Iniciação Científica teve como objetivo analisar, numa perspectiva histórica, os conteúdos, as recomendações e orientações de geometria a ensinar e para ensinar presentes no livro "Ensino atualizado da matemática" e em seu Guia do Professor referentes ao sétimo ano do primeiro grau, editados em 1974, por um grupo de professores da Bahia liderado por Omar Catunda (1906-1986) e Martha Maria de Souza Dantas (1925-2011).

Tal livro foi produto de uma série de ações dos professores desse grupo, que foi consolidado no decorrer da década de 1960 realizando pesquisas, produções e experimentações em espaços da Universidade Federal da Bahia, dentre eles, o Centro de Ensino de Ciências da Bahia, objetivando intervir no ensino e aprendizagem da matemática secundária. (LIMA; LANDO; FREIRE, 2013). Assim, a produção de livros feita pelo grupo da Bahia traduziu-se numa importante estratégia para que os professores fizessem uma apropriação de uma reformulação do ensino de matemática no âmbito das escolas secundárias baianas.

Por meio do discurso para aproximar a matemática praticada das instituições superiores daquela vista na escola secundária, foi desencadeada uma reestruturação nesse ensino durante o século $\mathrm{XX}$, dividida em dois períodos: o primeiro ocorreu na primeira metade do século XX e, o segundo, na segunda metade do século XX. No entanto, para o 
desenvolvimento da minha pesquisa me atentei somente a reestruturação pós segunda guerra, que ficou conhecido posteriormente como Movimento da matemática Moderna (MMM). De acordo com Guimarães (2007, p.21), houve: “[...] em comum a intenção de modificar os currículos do ensino da Matemática visando a actualização [sic] dos temas matemáticos ensinados, bem como a introdução de novas reorganizações curriculares e de novos métodos de ensino." Essa proposta, oficializada no Seminário de Royaumont, realizado em 1959, foi influenciada pela concepção estruturalista do Grupo Bourbaki em relação à matemática, na qual envolvia a unificação dos diversos ramos da matemática por meio da teoria dos conjuntos. A concepção estruturalista tinha convergia com as ideias de Jean Piaget, que, ainda, em 1952, “[...] defendeu a correspondência entre as estruturas matemáticas conhecidas, base de toda a 'arquitetura' bourbakista da Matemática [...] e as estruturas operatórias da inteligência, chegando mesmo a recomendar que tal facto deveria servir de base à didáctica da Matemática [...]” (GUIMARÃES, 2007, p. 23).

No Brasil a reformulação no ensino de matemática começou ser apropriada a partir da década de 1950, com as realizações de congressos nacionais que se consolidavam com o objetivo de "[...] discutir novas propostas com respeito à metodologia, treinamento e formação de professores, currículos, material didático, etc.” (SOARES, 2005, p. 2). Essa apropriação se deu de forma mais sistemática ao longo da década de 1960, por meio de grupos de estudos. Aqueles que mais se destacaram foram: o Grupo de Estudos do Ensino da Matemática (GEEM) em São Paulo, o Núcleo de Estudo e Difusão do Ensino da Matemática (NEDEM), no Paraná, Grupos de Estudos e Pesquisa em Educação Matemática (GEPEM), no Rio de Janeiro, e, na Bahia, a já citada SCM no CECIBA.

Em particular, na Bahia, para além dos livros didáticos produzidos visando ajudar os professores a trabalharem a matemática seguindo essas novas orientações, foi também publicado um Guia do Professor. Nestes termos, a pesquisa voltou-se para o ensino da geometria, que tinha quase desaparecido dos programas do curso secundário. Um indicativo neste sentido, segundo Leme da Silva (2005), foi o fato de que os cursos oferecidos pelo GEEM, “[...] no período entre 1960 a 1970, [...] a geometria não foi uma área muito discutida, apresentando um número bastante reduzido de cursos [...], se comparado aos demais." (LEME DA SILVA, 2005, p.75). Sob essa ótica a pesquisa torna-se relevante para uma historiografia da educação matemática que trata da reestruturação do ensino secundário de matemática.

\section{MATERIAL E MÉTODOS OU METODOLOGIA (ou equivalente)}

Para desenvolver o projeto de Iniciação Científica, em um primeiro momento, fiz leituras, discussões e sínteses de textos, no âmbito do LIAPEME e nas orientações individuais, que tratavam: 1) da pesquisa histórica (CARDOSO, 1986); 2) da história cultural (CHARTIER, 1988, 1995); 3) sobre livros didáticos (CHOPPIN, 2004; BITTENCOURT, 2011); 4) do ensino de geometria no período da modernização da matemática no secundário (GUIMARÃES, 2007; FREIRE, 2009; LIMA et al., 2010; LIMA; LANDO; FREIRE, 2013); 5) dos saberes a ensinar - objetos do ensino- e dos saberes para ensinar - saberes considerados como ferramentas para o professor exercer a sua profissão (HOFSTETTER; VALENTE, 2017; BERTINI; MORAIS; VALENTE, 2017). 
No segundo momento, iniciei a análise do livro didático "Ensino atualizado da matemática", referente ao sétimo ano e em seu Guia do Professor focando estritamente na parte de geometria. A localização do livro Ensino Atualizado da Matemática foi de fácil acesso, pois estava disponibilizado na biblioteca Central Julieta Carteado da Universidade Estadual de Feira de Santana e o seu Guia do Professor foi disponibilizado pela a professora Eliene Lima. Para analisar as relações dos saberes a ensinar e para ensinar, fiz primeiramente uma análise no livro e, posteriormente, no guia.

\section{RESULTADOS E/OU DISCUSSÃO (ou Análise e discussão dos resultados)}

Pelas análises feitas, tanto o livro como o guia introduzem a geometria a ensinar - neste caso, os conteúdos, bem como a geometria para ensinar- entre outros elementos, métodos, procedimentos, dispositivos, escolha dos saberes a ensinar e os estudos pedagógicos, vinculados às ciências da educação (BORER, 2017; HOFSTETTER; SCHNEUWLY, 2017; BERTINI; MORAIS; VALENTE, 2017) - sob uma concepção estruturalista. Portanto, de acordo com as propostas da reformulação que estava acontecendo no período. Na sua proposta, os autores afirmaram que o estudo de geometria euclidiana poderia ser iniciado por meio da geometria afim- que é o estudo dos espaços vetoriais - e, com a introdução do conceito de métrica, partir para o estudo da geometria euclidiana. Para tanto, defenderam que a geometria a ensinar deveria ser feita de forma linear. Além disso, afirmaram que o processo de ensino e aprendizagem deveria acontecer de forma individual e que a linearidade dos conteúdos estava ligada ao espaço vetorial.

Com isso percebi convergências com as ideias estruturalistas da matemática e também da psicologia, ao defenderem, neste último caso, que os alunos ao estudarem os conteúdos dessa forma poderiam alcançar três domínios, isto é, o domínio cognitivo, o domínio afetivo e o domínio psicomotor, os quais os autores defendiam ser necessários para alcançar os objetivos educacionais. Esses aspectos, na minha interpretação, configuram orientações que articulavam uma geometria a ensinar com uma geometria para ensinar.

\section{CONSIDERAÇÕES FINAIS (ou Conclusão)}

Os saberes geométricos presentes no livro didático Ensino Atualizado da Matemática do sétimo ano e no Guia, foram organizados de forma a possibilitar a apropriação dos professores que ensinavam nas escolas secundárias do ideário da matemática moderna. Dada a preocupação em produzir um livro direcionado exclusivamente para os estudos da geometria euclidiana, considero que, em convergência com outros autores, como a própria Freire (2010), que tais estudos continuou ocupando um espaço importante em um ideário de reformulação do ensino secundário de matemática. Contudo, um elemento complicador para a quase exclusão dos saberes geométricos nos programas curriculares parece ter residido na abordagem defendida para o seu ensino. Na Bahia, o grupo do SCM, isso foi feito a partir das transformações geométricas - isto é, "introdução da estrutura algébrica do conjunto das translações” (FREIRE, 2010, p. 378). $\mathrm{Na}$ época, considerada de difícil compreensão por uma gama de professores formados antes da inserção de novos conteúdos e de novas metodologias no ensino secundário da matemática, em particular, na geometria.

\section{REFERÊNCIAS}


BERTINI, Luciane de Fatima; MORAIS, Rosilda dos Santos; VALENTE, Wagner Rodrigues. A matemática a ensinar e a matemática para ensinar: novos estudos sobre a formação de professores. São Paulo: Livraria da Física, 2017.

BITTENCOURT, Circe Maria Fernandes. Em foco: história, produção e memória do livro didático. Educação e Pesquisa, São Paulo, v.30, n. 3, [n.p], set./dez. 2004. Disponível em: http://www.scielo.br/pdf/ep/v30n3/a07v30n3.pdf. Acesso em: 19 fev. 2011.

BORER, Valérie Lussi. Os saberes: uma questão crucial para a institucionalização da formação de professores. In: HOFSTETTER, R; VALENTE, W. R. (org.). Saberes em (trans)formação: tema central da formação de professores. São Paulo: Livraria da Física, 2017. p. 173-199.

CARDOSO, Ciro Flamarion S. Uma introdução à História. 5. ed. São Paulo: Brasiliense, Série Coleção Primeiros Vôos, 1986.

CATUNDA, Omar et al. Ensino atualizado da matemática: $5^{\text {a }}$ série, $1^{\circ}$ grau. 3 . ed. rev. São Paulo, EDART, 1974.

CATUNDA, Omar et. al. Ensino atualizado da matemática: $5^{\mathrm{a}}$ a $8^{\mathrm{a}}$ séries, $1^{\mathrm{o}}$ grau, Guia do professor. São Paulo: EDART, 1974.

CHARTIER, Roger. A história cultural: entre práticas e representações. Tradução de Maria Manuela Galhardo. Lisboa: Difel, 1988.

CHARTIER, Roger. Cultura popular: revisitando um conceito historiográfico. Estudos

Históricos, v. 8, n.16, p. 179-192, 1995. Disponível em: http://bibliotecadigital.fgv.br/ojs/index.php/reh/article/view/2005/1144. Acesso em: 12 out. 2013.

CHOPPIN, Alain. História dos livros e das edições didáticas: sobre o estado da arte.

Educação e Pesquisa, São Paulo, v.30, n. 3, p. 549-566, set./dez. 2004. Disponível em: < http://www.scielo.br/pdf/ep/v30n3/a12v30n3.pdf>. Acesso em: 16 fev. 2011.

FREIRE, Inês Angélica Andrade. Ensino de Matemática: iniciativas inovadoras no Centro de Ensino de Ciências da Bahia (1965-1969). 2009. 102 f. Dissertação (Mestrado em Ensino, Filosofia e História da Ciência)- Instituto de Física, Universidade Federal da Bahia, Salvador, 2009.

HOFSTETTER, Rita; SCHNEUWLY, Bernard. Saberes: um tema central para as profissões do ensino e da formação. HOFSTETTER, Rita; VALENTE, Wagner Rodrigues (org.). Saberes em (trans)formação: tema central da formação de professores. São Paulo: Livraria da Física, 2017. p. 113-172.

GUIMARÃES, Henrique Manuel. Por uma matemática nova nas escolas secundárias perspectivas e orientações curriculares da matemática moderna. In: Matos, José Manuel; VALENTE, Wagner Rodrigues. (Org.) A Matemática Moderna nas escolas do Brasil e Portugal: primeiros estudos. São Paulo: Zapt Editora, 2007.p. 21-45.

LEME DA SILVA, Maria Célia. A Geometria escolar ontem e hoje: algumas reflexões sobre Livros Didáticos de Matemática. UNIÓN: Revista Iberoamericana de Educación Matemática, San Cristobal de La Laguna, n. 3, p. 73-85, sept. 2005.

LIMA, Eliene Barbosa et al. A institucionalização da matemática moderna nos currículos escolares ou a hegemonia da cultura matemática científica nas escolas. In: JORNADAS LATINOAMERICANAS DE ESTUDIOS SOCIALES DE LA CIENCIA Y TECNOLOGIA, 8., 2010, Buenos Aires. Anais...[ S.I.: s.n], 2010, 1CD ROM, p. 119.p. 15.

LIMA, Eliene Barbosa; LANDO, Janice Cássia; FREIRE, Inês Angélica Andrade. A Coleção Didática Ensino Atualizado da Matemática: o guia do professor. In: CONGRESSO IBEROAMERICANO DE EDUCACIÓN MATEMÁTICA, 7., 2013. Actas [...], Montevidéu, Uruguai, 2013. 